\title{
Calculation methodology of marine environmental capacity for heavy metal: A case study in Jiaozhou Bay, China
}

\author{
LI KeQiang \& WANG XiuLin* \\ Key Laboratory of Marine Chemistry Theory and Technology, Ministry of Education; College of Chemistry and Chemical Engineering, Ocean \\ University of China, Qingdao 266100, China
}

Received February 21, 2012; accepted March 30, 2012; published online August 16, 2012

\begin{abstract}
Results from past pollution control practices show that environmental quality can be ensured by controlling the actual amount of pollutants formed in the environment. Therefore, the marine environmental capacity for heavy metals was introduced. Marine environmental capacity for heavy metals is defined as the maximum amount of heavy metals permitted in the marine environment system to preserve the benign cycle of materials in the oceansphere, and to limit the adverse effects of heavy metals on the biosphere, hydrosphere, atmosphere, and lithosphere. Based on the box or three-dimensional model in the target coastal region, including the self-purification and output of heavy metals, the marine environmental capacity for heavy metals can be calculated within a given criterion and time. In this study, a method was proposed to calculate the marine environmental capacity for heavy metals which includes four steps: (1) gathering the basis information of target coastal ecosystem, (2) selection of water control points and water quality criteria for these points, (3) development of numerical models for the biogeochemical cycling of heavy metals in target coastal region, and (4) calculation of environmental capacity using the developed model. According to the proposed method, the marine environmental capacity for lead is approximately 60 tons per year if Grade I seawater quality is set as the control criterion in Jiaozhou Bay. An effective seawater quality management plan can also be framed based on the environmental capacity for metals.
\end{abstract}

marine environmental capacity, calculation methodology, lead, model, Jiaozhou Bay

Citation: $\quad$ Li K Q, Wang X L. Calculation methodology of marine environmental capacity for heavy metal: A case study in Jiaozhou Bay, China. Chin Sci Bull, 2013, 58: 282-287, doi: 10.1007/s11434-012-5395-5

Most coastal areas in the world have been reportedly damaged by heavy metal pollution, significantly affecting commercial coastal and marine fisheries [1]. Heavy metal pollution is an important problem due to its toxic effect and accumulation throughout the food chain, which leads to serious ecological and health hazards resulting from the heavy metals' solubility and mobility [2]. Therefore, the control of aquatic heavy metal pollution is urgently needed for the sustained management and conservation of existing fisheries and aquatic resources. Varying amounts of different heavy metals, discharged as waste into the coastal marine environment, are by-products of many industrial processes [3-5]. Thus, effective coastal management requires the control of

*Corresponding author (email: xlwang@ouc.edu.cn) total land-based input loads, which are determined by their environmental capacity. Estimating the pollutant marine environmental capacity is crucial for efficient coastal water management, policy, and sustainable coastal area use [6].

Extensive and systematical studies on marine environmental capacity for pollutants, such as nutrients, metals and petroleum hydrocarbons, were done in Jiaozhou Bay, China [7-12]. These studies involved calculation methods for marine environmental capacity and applications in pollution control. While, these methods most are based on box model [7-10], which can not be used on three-dimensional (3D) model, and some are based on 3D model [11,12], whose results do not represent the marine environmental capacity but the allocation capacity for sources. Based on these earlier studies, the calculation method for marine environmental 
capacity in the current work must be clarified and normalized to be used on 3D model. Therefore, the present paper mainly discussed the methodology research on marine environmental capacity for pollution in the coastal marine environment. A method was proposed to calculate the marine environmental capacity for heavy metals, and lead is chosen as a case of heavy metal pollution in Jiaozhou Bay, China.

\section{Methodology}

\subsection{Concept of environmental capacity}

Environmental capacity, first used by Nishimura [13] in a marine environment, is defined by the Joint Group of Experts on the Scientific Aspects of Marine Environmental Protection (GESAMP) as the ability of an environment to accommodate a particular activity or rate of activity without any unacceptable impact [14]. When the concept is applied to semi-enclosed coastal areas, it can be defined as the maximum amount of heavy metals permitted in the marine environment system to preserve the benign cycle of materials in the oceansphere, and to limit the adverse effects of heavy metals on the biosphere, hydrosphere, atmosphere, and lithosphere. The factors contributing to marine environmental capacity include hydrodynamic transport self-purification, sedimentation transport self-purification, biological self-purification (such as bioconcentration, biomagnification, and biodegradation), and chemical self-purification [10,15].

Based on the concept of marine environmental capacity, a method was proposed to calculate the marine environmental capacity for heavy metals. This proposed method includes four steps: (1) gathering the basis information of target coastal region, (2) selection of water control points and water quality criteria for these points, (3) development of numerical models for the biogeochemical cycling of heavy metals in target coastal region, and (4) calculation of environmental capacity using the developed model.

\subsection{Gathering basic information and setting up water control points}

Basic information is necessary to determine environmental capacity. Such information include the natural environment conditions, the characteristics of the target coastal region involving the pollution sources and study area, the effects of heavy metal on marine organisms, and other environmental factors in the region involving dynamic formulations and parameters. These pollution sources should consist of all actual and potential sources in future based on the land-sea boundary.

The water quality control points and the criteria for heavy metals in the marine environment are key factors in determining its environmental capacity. The former refers to the locations of possible peak concentration points of heavy metals around the sources while the latter refers to the highest concentration of heavy metals in the water quality control points. These criteria are the levels at which marine organisms can grow normally or the contents of heavy metals no higher than the limits set by National Seawater Quality Standards. Notably, these criteria should be based on environmental state, types of water usage, and management policy.

\subsection{Setting up the numerical model}

Numerical model is essential to improve the understanding of hydrodynamic, biological, and chemical processes of heavy metals in the marine environment. It may be applied further to evaluate plans for water quality management [16-18]. Water quality can be predicted by models based on the environmental variation in coastal areas [19]. Then, pollutant environmental capacity can be calculated based on a criterion of heavy metals.

When heavy metals enter the marine environment through atmospheric and land-based effluent sources [4,20], the "dissolved" phase containing free metal ions as well as complexed and colloidally bound metal species is subjected to a variety of physical, biological, and chemical processes for the self-purification of water (Figure 1). These processes may include physical self-purification such as transport to the out sea by hydrodynamic processes; biological selfpurification such as bio-concentration by phytoplankton and other aquatic organisms as well as transfer from lower to higher trophic levels in food webs; and chemical self-purification such as adsorption by suspended particulate matter and sediments, and the sedimentation and physical entrapment of enriched particulate matter [21-24]. Allan pointed out that particulate matter is an extremely important substrate for the transportation of metals in marine systems [25].

Numerical models for the marine environmental capacity of metals are based on dynamic formulations involving a few variables and parameters for the transportation and transformation processes of metals in the target coastal region. These numerical models may be a box or a 3D model coupled biogeochemical-hydrodynamic processes according to the natural environment conditions and characteristics of the target coastal region [10]. Based on the models, three modules are involved. These modules include metal input, uptake of metals by sediments and suspended particulates involving biotic (phytoplankton and bacteria) and abiotic (inorganic and organic) particulates, and transport to the out sea by hydrodynamic processes.

(1) Box model. A box model can be used if the target coastal region is instantaneously mixed and weak stratified either vertically or horizontally [26]. The basic equation describing the time and space evolution of a metal is as follows [10]:

$$
\mathrm{d} C / \mathrm{d} t=S+D_{\mathrm{SS}}+O
$$




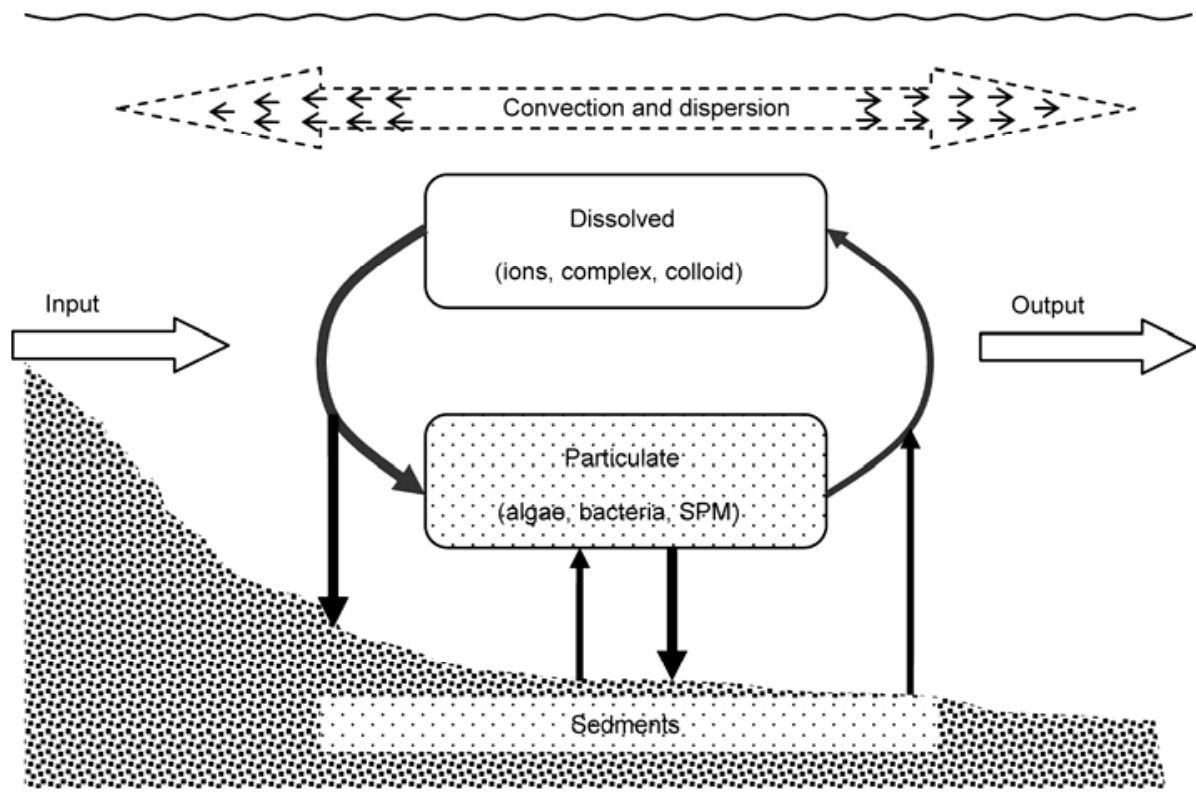

Figure 1 Transportation and transformation of metals (such as lead) in the coastal marine environment. SPM represents the suspended particulate matter.

$$
\begin{gathered}
D_{\mathrm{SS}}=\left(v_{\mathrm{S}} / H\right) k_{\mathrm{S}} \cdot C \cdot C_{\mathrm{S}}, \\
O=k_{\text {hyd }} \cdot\left(C-C_{\text {out }}\right),
\end{gathered}
$$

where $C$ is the concentration of the metal variable, $S$ is the source term, $D_{\mathrm{SS}}$ is the uptake of metal by sediments and suspended particulates, $O$ is the output term by hydrodynamic process, $H$ is the total water depth (mean sea level plus free surface elevation), $v_{\mathrm{S}}$ refers to the sinking speed of suspended particulates, $k_{\mathrm{S}}$ refers to the thermodynamic partition coefficient between dissolved metals and suspended particulates [24], $k_{\text {hyd }}$ refers to the hydrodynamic exchanging coefficient with the out sea, and $C_{\mathrm{S}}$ and $C_{\text {out }}$ are the concentrations of suspended particulates and metal in the out sea, respectively.

(2) Three-dimensional coupled biogeochemical-hydrodynamic model. The 3D model will probably be employed if the target coastal region is not spatially uniform and the peak concentration at a point is required [26]. The coupled biogeochemical-hydrodynamic model uses the hydrodynamic model by driving it with the output of physical circulation and dispersion models. Irradiance and temperature are supplied as external forcing. The general evolution equation for the concentration variation of standing stock $C$ at a given time is

$$
\begin{aligned}
\frac{\partial C}{\partial t}= & -u \cdot \frac{\partial C}{\partial x}-v \cdot \frac{\partial C}{\partial y}-w \cdot \frac{\partial C}{\partial z}+\frac{\partial}{\partial x}\left(A_{\mathrm{h}} \cdot \frac{\partial C}{\partial x}\right) \\
& +\frac{\partial}{\partial y}\left(A_{\mathrm{h}} \cdot \frac{\partial C}{\partial y}\right)+\frac{\partial}{\partial z}\left(A_{\mathrm{v}} \cdot \frac{\partial C}{\partial z}\right)+S+D_{\mathrm{SS}},
\end{aligned}
$$

where $C$ is the concentration of the metal variable; $t$ is time; $u, v$, and $w$ are the mean velocity components; $A_{\mathrm{h}}$ and $A_{\mathrm{v}}$ refer to the horizontal and vertical eddy diffusion coefficients, respectively; $S$ is the source term; and $D_{\mathrm{SS}}$ is the uptake of metal by sediments and suspended particulates. The standing stock of the variable is predicted with temporal and spatial changes by entering the velocity components calculated by hydrodynamic modeling into the model.

\subsection{Marine environmental capacity calculation approach}

Based on the proposed models, marine environmental capacity refers to the maximum amount of heavy metals in the target coastal region within a given criterion and time, which includes the self-purification and output of heavy metals in that marine system. It can be expressed as eq. (5) based on the box model and as eq. (6) based on the 3D model:

$$
\begin{gathered}
\mathrm{EC}=\max \left\{\left.V \cdot \int_{0}^{t}\left[\left(\frac{\mathrm{d} C}{\mathrm{~d} t}\right)-D_{\mathrm{SS}}-O\right]\right|_{C \leqslant C^{\mathrm{s}}} \mathrm{d} t\right\}, \\
\mathrm{EC}=\max \left\{\left.\int_{0}^{V} \int_{0}^{t}\left[\left(\frac{\partial C}{\partial t}\right)-D_{\mathrm{SS}}-\left(\frac{\partial C}{\partial V}\right)_{\mathrm{Hyd}}\right]\right|_{C_{i} \leqslant C^{\mathrm{s}}} \mathrm{d} V \mathrm{~d} t\right\},
\end{gathered}
$$

where EC refers to the environmental capacity of the target coastal region for the metal, $C$ and $V$ are the current concentration and volume in the region, respectively, $C_{i}$ is the concentration of the $i$ th water quality control point, $C^{\mathrm{s}}$ is the criteria of the metal, $D_{\mathrm{SS}}$ is the uptake of metal by sediments and suspended particulates, and $O$ and $\left(\frac{\partial C}{\partial V}\right)_{\text {hyd }}$ are output metals by the hydrodynamic process. Then, environmental capacity can be calculated by integrating the grads of 
pollution concentration field in time and/or space using the developed model.

\section{Case study in Jiaozhou Bay}

\subsection{Study region and basic information}

Jiaozhou Bay $\left(35^{\circ} 58^{\prime}-36^{\circ} 18^{\prime} \mathrm{N}, 120^{\circ} 04^{\prime}-120^{\circ} 23^{\prime} \mathrm{E}\right)$ is a semi-enclosed bay connected to the Yellow Sea by a $2.5 \mathrm{~km}$ channel. Bordered by the city of Qingdao on three sides, it is located in the southern coastal area of Shandong Peninsula, China (Figure 2). The bay, with a mean depth of $7 \mathrm{~m}$, extends $33 \mathrm{~km}$ from north to south and $28 \mathrm{~km}$ from west to east [27]. More than 10 small seasonal rivers empty into the bay with varying water and metals loads, including Dagu River, Moshui River, Loushan River, Licun River, and Habo River. Most of these rivers have become discharge trenches for industrial and domestic waste. Most are outlets of sewage treatment plants in Qingdao City, such as the Haibohe, Licunhe, Loushanhe, and Chengyang plants. Lead pollution of approximately 50 tons loading per annum has become one of the most serious environmental concerns in Jiaozhou Bay [10,28]. Water mass movement in this bay is dominated by tidal events, with strong residual currents at the bay mouth and weak at the inner bay [29]. Liu et al. [30] measured the average residence time to be approximately 52 d, whereas Zhao et al. [31] measured it at $80 \mathrm{~d}$. Stratification is weak, with limited freshwater flux and a strong mix of tidal turbulence $[30,32,33]$.

\subsection{Modeling}

A 3D biogeochemical-hydrodynamic model for lead is developed to calculate Jiaozhou Bay's environmental capacity based on the flow fields caused by the tidal and density currents combined with the biogeochemical cycles of lead. The model has two components, a hydrodynamic model [34] for water flow simulation and a biogeochemical model [9] for lead transportation and transformation. Tidal and residual currents are simulated by the hydrodynamic model component [34,35] based on the Estuarine, Coastal, and Ocean Modeling System with Sediments [36]. A spatially curvilinear orthogonal system with $128 \times 92$ grids is adopted to model the study area (Figure 3 ). Vertical resolution is accomplished using $11 \sigma$-levels in the water column, and the tidal amplitude and phase of M2 are considered on the open boundary [34]. Biogeochemical parameters mainly include the sinking speed of suspended particulates $\left(v_{\mathrm{S}}\right)$ and the thermodynamic partition coefficient $\left(k_{\mathrm{S}}\right)$, which are approximately $2 \times 10^{-6} \mathrm{~m} / \mathrm{s}$ [15] and $0.2 \times 10^{6}$ to $8 \times 10^{6} \mathrm{~L} / \mathrm{kg}$ for lead [37], respectively. Based on the evaluation and prediction of the biogeochemical-hydrodynamic model, the environmental capacity of lead is calculated with a time increment of $186.3 \mathrm{~s}$ and the finite difference methods for evaluating the basic equations numerically.

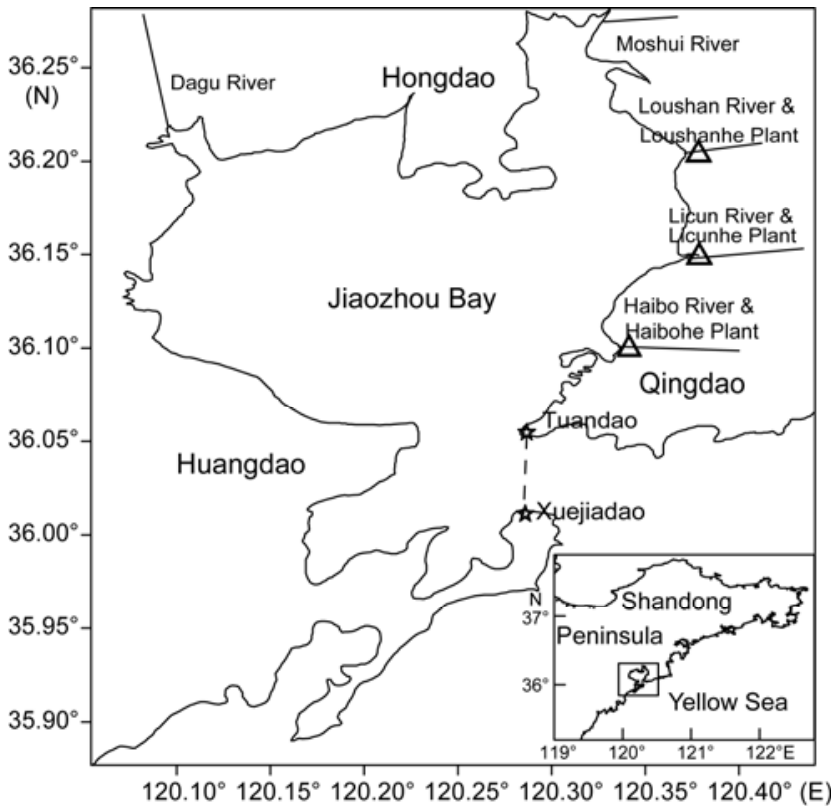

Figure 2 Map of Jiaozhou Bay showing the Dagu, Moshui, Loushan, Licun, and Haibo rivers, the sewage treatment plants of Haibohe, Licunhe, and Loushanhe $(\Delta)$, and the bay mouth (Tuandao-Xuejiadao cross-section) (穴).

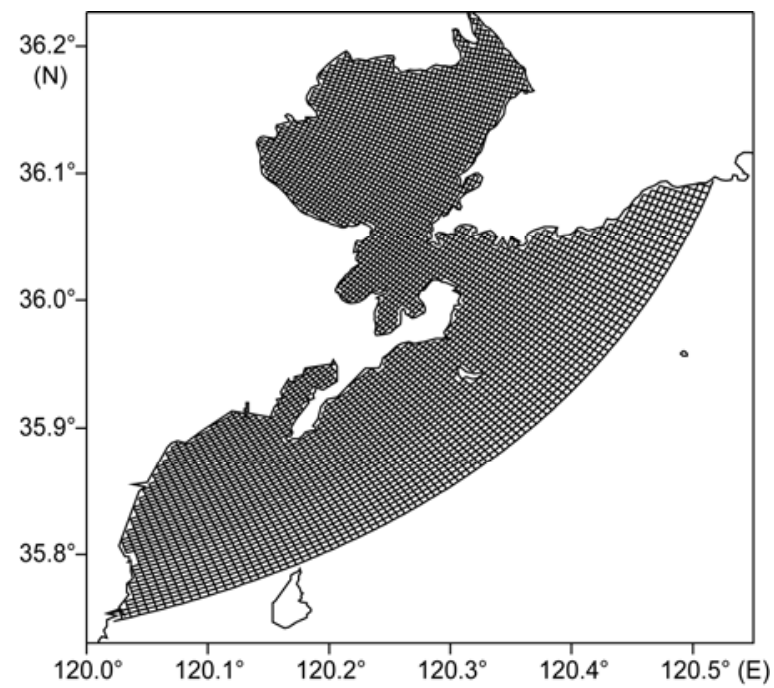

Figure 3 Model grid for 3D circulation model of Jiaozhou Bay. The curvilinear orthogonal grid allows the mesh resolution to vary spatially, with $600 \mathrm{~m}$ minimum grid spacing, $284 \mathrm{~m}$ minimum spacing, and $686 \mathrm{~m}$ maximum spacing. There are currently 10 vertical $\sigma$-levels evenly spaced throughout the water column in the model.

\subsection{Result and discussion}

(1) Water quality simulation. The simulated summer surface distribution of lead concentration in Jiaozhou Bay in 2001 based on the proposed model is shown in Figure 4. The higher values, ranging from 0.25 to $2.8 \mu \mathrm{g} / \mathrm{L}$, are near sources of estuaries for allochthonous lead from input sources such as rivers and treated wastewater from Qingdao. 


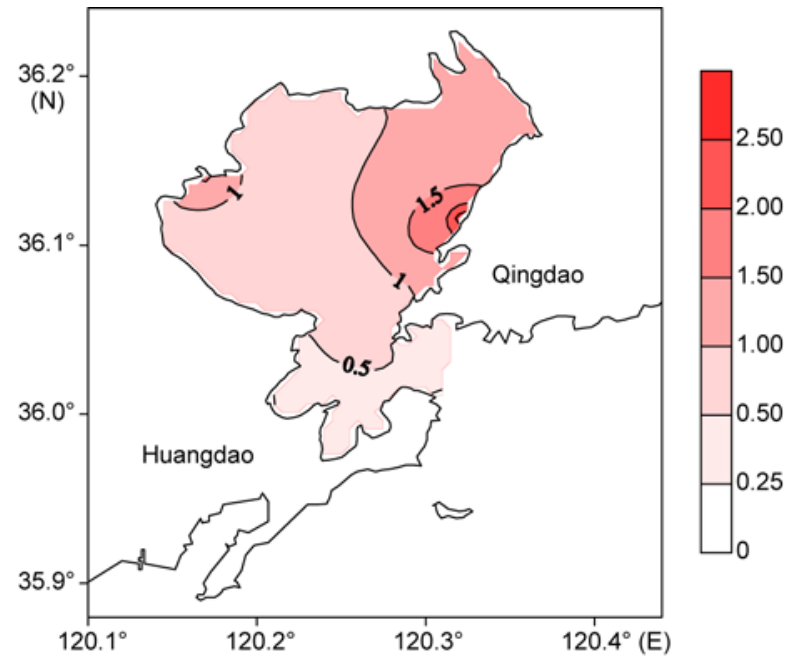

Figure 4 Simulation results of surface lead concentration in Jiaozhou Bay in the summer in 2001 (unit: $\mu \mathrm{g} / \mathrm{L}$ ).

In the outer part of the bay, lead concentration is decreased by dilution and diffusion caused by rapid seawater exchange current through the narrow channel. The pattern and values of water quality exceeding Grade I water standard $(1 \mu \mathrm{g} / \mathrm{L})$ in the east of the bay and the peak in the estuary of Haibo River matches the observed values by Wang et al. [10] reasonably well. The built model can then be used to calculate Jiaozhou Bay's environmental capacity for lead.

(2) Calculation of marine environmental capacity. The calculation area is the whole region of Jiaozhou Bay, the outer boundary of which is the bay mouth (Tuandao-Xuejiadao cross-section) (Figure 2). All neighboring grids of the land-based and fictitious sources, always at the peak concentration points, are set as the water quality control points. Grade I seawater quality of lead $(1 \mu \mathrm{g} / \mathrm{L})$ is set as the control criterion in Jiaozhou Bay. To reach and maintain the chosen criterion, the marine environmental capacity for lead was calculated using the numerical model. The maximum self-purification and output amount, which is the environmental capacity for lead in Jiaozhou Bay, is approximately 60 tons for one year. This amount is a little higher than the environmental capacity by the box model, which is 40 tons lead per year [10]. These results reflect Jiaozhou Bay's loading capacity for lead.

Controlling pollutant loads in accordance with the environmental capacity is important and must be made top priority in the management of total amount control. The more important process in the management of total amount control in a bay is the control of pollutant loads from landbased sources, which is allocated according to the environmental capacity [8]. An effective seawater quality management plan must also be framed based on the environmental capacity for metals, which involves structural optimization and technological measurement in the industry, and constant monitoring and systematic management of pollution sources.
The authors would like to thank Dr. Xianwen Bao for providing us with the hydrodynamic model (ECOMSED) in Jiaozhou Bay and Dr. Xiuquan Wan for his assistance in modeling. The authors also gratefully acknowledge the provision of the data of river water discharge, waste discharge and concentrations distributions from the Qingdao Environment Monitoring Centre. This work was supported by the Science Fund Projects of Shandong Province (ZR2010DM005), the National high Technology Research and Development Program (2010BAC69B01), and Science and Technology Development Plan of Qingdao (11-2-3-66-nsh and 11-2-1-18-hy).

1 Islam M S, Tanaka M. Impacts of pollution on coastal and marine ecosystems including coastal and marine fisheries and approach for management: A review and synthesis. Mar Poll Bull, 2004, 48: 624-649

2 Davies A G. Pollution studies with marine plankton. Part II. Heavy metals. Adv Mar Biol, 1978, 15: 381-508

3 James P M, Syvitski C J, Vörösmarty A J, et al. Impact of humans on the flux of terrestrial sediment to the global coastal ocean. Science, 2005, 308: 375-380

4 GESAMP (Joint Group of Experts on the Scientific Aspect of Marine Pollution). Land/sea boundary flux of contaminants: Contributions from rivers. Rep Stud 32. UNESCO, 1987. 180

5 Robson A J, Neal C. A summary of regional water quality for Eastern UK Rivers. Sci Total Environ, 1997, 194/195: 15-37

6 USEPA (United States Environmental Protection Agency). Technical Guidance Manual for Developing Total Maximum Daily Loads. EPA 823-B-97-002. US. Environmental Protection Agency, Office of Research and Development, Washington DC. 1997

7 Ge M, Wang X L, Yan J, et al. The calculation of environmental capacities of nutrients of nutrients in Jiaozhou Bay (in Chinese). Mar Sci, 2003, 27: 36-42

8 Li K Q, Wang X L, Deng N N, et al. Calculation of environmental capacity of petroleum hydrocarbon in Jiaozhou Bay. Mar Sci Bull, 2004, 6: 53-59

9 Li J L, Li K Q, Wang X L, et al. Study on model of transport and transformation of lead (II) in multimedia environment of Jiaozhou Bay (in Chinese). Mar Environ Sci, 2009, 28: 516-521

10 Wang X L, Li K Q, Shi X Y. The Marine Environmental Capacity of Major Pollutants in Jiaozhou Bay (in Chinese). Beijing: Science Press, 2006. 293

11 Han H Y, Li K Q, Wang X L, et al. Environmental capacity of nitrogen and phosphorus pollutions in Jiaozhou Bay, China: Modeling and assessing. Mar Poll Bull, 2011, 63 : 262-266

12 Qian G D, Shi X Y, Li K Q, et al. Estimation of environmental capacity of petroleum hydrocarbons in jiaozhou bay, China. Fresen Environ Bull, 2012, 21: 48-53

13 Nishimura J. The conception of environmental capacity (in Japanese). Mar Sci, 1977, 87: 42-45

14 GESAMP. Environmental capacity, an approach to marine pollution prevention. Rep Stud 30. FAO Rome, 1986. 62

15 Wang X L, An Y, Zhang J, et al. Contribution of biological processes to self-purification of water with respect to petroleum hydrocarbon associated with no.0 diesel in Changjiang Estuary and Jiaozhou Bay, China. Hydrobiologia, 2002, 469: 179-191

16 Nobre A M, Ferreira J G, Nunes J P, et al. Assessment of coastal management options by means of multilayered cosystem models. Estuar Coast Shelf Sci, 2010, 87: 43-62

17 Takeshi $\mathrm{H}$. The role of modelling in the control of seawater pollution. Wat Sci Technol, 1988, 20: 277-286

18 Yanagi $\mathrm{T}$, Inoue $\mathrm{K}$, Montani $\mathrm{S}$, et al. Ecological modeling as a tool for coastal zone management in Dokai Bay, Japan. J Mar Syst, 1997, 13: 123-136

19 Blumberg A F, Signell R P, Jenter H L. Modelling transport processes in the coastal ocean. J Mar Environ Eng, 1993, 1: 31-52

20 GESAMP. The atmospheric input of trace species to the world ocean. Rep Stud 38. WMO, 1989. 124

21 Hart B T. Uptake of trace metals by sediments and suspended particulates: A review. Hydrobiologia, 1982, 91: 299-313

22 Holan Z, Volesky B. Biosorption of lead and nickel by biomass of 
marine algae. Biotechnol Bioeng, 1994, 43: 1001-1009

23 Jammasch H W, Honeyman B D, Balistrieri L S, et al. Kinetics of trace metal uptake by marine particles. Geochim Cosmochim Acta, 1988, 52: 567-577

24 Olsen C R, Cutshall N H, Larse I L. Pollutant-particle associations and dynamics in coastal marine environments: A review. Mar Chem, 1982, 11: 501-533

25 Allan R J. Sediment-related fluvial transmission of contaminants: Some advances by 1979. Inland Waters Directorate, Environment Canada, Scientific Series No. 107, 1979. 24

26 GESAMP. Coastal modelling. Rep Stud 43. IAEA Vienna, 1991. 191

27 Editorial Board of Bays in China. Bays in China (Vol. 4) (in Chinese). Beijing: Ocean Press, 1993. 157-260

28 Shandong Provincial Ocean and Fishery Department. 2003 Official Gazettes of Ocean Environment Quality of Shandong Province (in Chinese), Jiannan. 2004

29 Sun Y L, Chen S J, Yu G Y. Study on the analysis of physical self-purification capability and water quality prediction of Jiaozhou Bay (in Chinese). J Shandong Coll Oceanol, 1988, 18: 60-66

30 Liu Z, Wei H, Liu G, et al. Simulation of water exchange in Jiaozhou Bay by average residence time approach. Estuar Coast Shelf Sci,
2004, 61: 25-35

31 Zhao L, Wei H, Zhao J Z. Numerical study on water exchange in Jiaozhou Bay (in Chinese). Chin J Oceanol Limnol, 2002, 33: 23-29

32 Ding W L. Tides and tidal currents. In: Liu R Y, ed. Ecology and Living Resources of Jiaozhou Bay (in Chinese). Beijing: Science Press, 1992. 39-57

33 Weng X, Zhu L, Wang Y. Physical oceanography. In : Liu R Y, ed. Ecology and Living Resources of Jiaozhou Bay (in Chinese). Beijing: Science Press, 1992. 20-29

34 Bao X W, Yan J, Zhao L, et al. Application of ecom to simulate tidal currents in Jiaozhou Bay (in Chinese). Mar Sci, 1999, 23: 57-60

35 Wan X Q, Bao X W, Wu D X, et al. Numerical simulation of the tidal currents and the pollutant diffusion in jiaozhou bay (in Chinese). Mar Sci, 2003, 27: 31-36

36 Blumberg A F, Mellor G L. A description of a three-dimensional coastal ocean circulation model. In: Heaps N S, ed. Three-Dimensional Coastal Ocean Model. Washington DC: American Geophysical Union Press, 1987. 1-16

37 Li J X, Du R G, Zhang G X, et al. The transportion and sink of heavy metals $(\mathrm{Cd}, \mathrm{Cu}, \mathrm{Pb}, \mathrm{Zn}, \mathrm{Hg})$ in the marin mesocosm ecosystem in Xiamen (in Chinese). Acta Oceanol Sin, 1989, 11: 207-217

Open Access This article is distributed under the terms of the Creative Commons Attribution License which permits any use, distribution, and reproduction in any medium, provided the original author(s) and source are credited. 